Fecha de recepción: febrero 2019 Fecha de aceptación: marzo 2019 Versión final: mayo 2019

\section{Memorias y (des)memorias de la dictadura. Una lectura de La mujer sin cabeza, de Lucrecia Martel}

Marta Casale *

Resumen: El film, de 2008, propone una historia en la que fácilmente pueden encontrarse correspondencias con la desaparición de personas durante la dictadura militar argentina: la desaparición de un cuerpo, un probable crimen que es eficientemente ocultado, la corrupción y la complicidad. Pero, tras la interpretación alegórica más evidente, aparece la posibilidad de otra menos obvia que, por un lado, la refrenda y, por el otro, la cuestiona, a través, sobre todo, de procedimientos formales. De este modo, el relato plantea dos lecturas que, sin embargo se vinculan, relacionando, además, presente y pasado: los desaparecidos de ayer son los invisibilizados de hoy, fruto de un régimen que se propaga, más allá de los límites de la dictadura, a través de políticas económicas neoliberales que los excluyen. Al poner nuevamente en foco estas cuestiones, la película interpela moralmente al espectador sobre su propio rol en dichos contextos.

Palabras clave: Dictadura - silencio - complicidad - desaparecidos - neoliberalismo - invisibilización

[Resúmenes en inglés y portugués en las páginas 133 - 134]

${ }^{(*)}$ Licenciada en Artes Combinadas (UBA). Profesora de Filosofía (UCA). Coautora de Una historia del cine político y social en Argentina, Vol.I y II (Nueva Librería, 2009 y 2011) y del Diccionario biográfico estético del actor en Buenos Aires Vol. I (Galerna, 2009). Forma parte del Instituto de Historia del Arte argentino y latinoamericano (UBA) investigando tanto en el área de cine como de teatro. Ha publicado artículos en distintos medios académicos del país y del exterior y participado en Congresos tanto a nivel nacional como internacional. Ha formado parte del Comité Editor de la Revista Afuera - Crítica Cultural (2008- 2010), como así también del referato para publicaciones como Tempo e Argumento (Universidadade do Estado de Santa Catarina, Brazil), Revista E-verba (Universidad Nacional Arturo Jauretche y el Departamento de Lenguas Modernas de Berkeley City College), Política y Cultura (Universidad Autónoma Metropolitana, México) y Nuevo mundoMundos nuevos (Francia). Actualmente integra el proyecto UBACyT 20020170200131BA "Condiciones laborales en las artes y la cultura". 
"Memory, especially historical memory, is a matter of perspective". Phillip Lee and Pradip Ninan Thomas, Public Media and the Right to Memory.

"[La memoria] es el producto de una serie de decisiones sobre qué y cómo retener lo que hoy se recuerda. La memoria es selectiva y contingente." Héctor Schmuder en el prólogo a Del estrado a la pantalla: las imágenes del juicio a los ex comandantes de Claudia Feld.

\section{Introducción}

Tercer film del conjunto que los estudios sobre la cineasta argentina han dado en llamar "la trilogía salteña" ${ }^{1}$, La mujer sin cabeza (2008) tiene algunas similitudes con sus anteriores trabajos y muchas diferencias, razón por la cual, quizás, la directora la calificó como su "película más argentina" (Enríquez, 2008). Si bien ciertos procedimientos estéticos se repiten, tales como la construcción de atmósferas opresivas o el sentimiento de encierro (son su marca estilística), otros recursos adquieren un matiz distinto: las referencias se tornan más locales, la focalización en una única protagonista más notoria y la historia puede considerarse, comparativamente, más lineal; ciertos tópicos se vuelven explícitos y cuestiones abordadas de sesgo en otros films se tematizan.

Aunque carece de anclaje temporal expreso, puede situarse el relato entre fines de los noventa (gobierno de Menem) y la fecha de su estreno (2008), ya que siempre tendemos a pensar que la acción es contemporánea si no se muestran claras señales de lo contrario ${ }^{2}$. Por otra parte, el contexto de provincia dificulta tomar ciertas marcas como de una temporalidad específica, ya que podemos suponer - tal vez prejuiciosamente- un estilo de vida algo diferente al de las grandes urbes, no tan pendiente de los últimos modelos de vehículos o dispositivos tecnológicos, que son los que permitirían fechar con mayor precisión la acción. Esta falta de datación concreta es relevante a la hora de referenciar el film directamente a la última dictadura (1976-1983), ya que al no haberla, cualquier vinculación debe darse a través de una especie de salto alegórico que permita relacionar tiempos distintos a través de lecturas más amplias.

En este sentido, si bien nada en el film sugiere un gobierno dictatorial en el presente de la diégesis, es innegable que propone una historia en la que con facilidad pueden encontrarse correspondencias con la desaparición de personas durante el régimen militar en la Argentina: un adolescente desaparecido, un probable crimen que es eficientemente ocultado, la corrupción y la complicidad que lo permiten.

Vero (María Onetto), una mujer de mediana edad y clase acomodada, tiene un accidente al salir de una reunión social, mientras maneja de regreso a su hogar por una ruta casi desierta una tarde soleada. Como resultado de una distracción al querer atender el celular que suena con insistencia, lejos de su alcance, atropella algo o a alguien. El espectador es testigo de los dos golpes que la sacuden y hacen que se detenga abruptamente, aunque no descienda del vehículo a comprobar con exactitud el daño que infligió. A pesar de 
que por el espejo retrovisor solo puede divisarse un perro tendido en mitad del camino, es imposible para quienes vieron antes al animal jugar con tres adolescentes al borde de la ruta, no plantearse al menos la posibilidad de que haya otra víctima. Solo cuando está lejos, Vero se detiene y baja para evaluar el efecto del choque en el auto. A partir de ese momento, que precede a los títulos que nombran a la protagonista como "sin cabeza", el relato irá serpenteando entre dudas y certezas. Vero perderá si no la memoria -aunque esto es indudablemente lo que le sucede al principio-, al menos su relación cotidiana con las cosas. Al mismo tiempo que parece estrenar una nueva mirada frente a todo cuanto la rodea, una de descubrimiento, se irá tendiendo en torno suyo una red de contención, pero también de ocultamiento; una red tejida, fundamentalmente, por los hombres de su familia. Si hubo crimen, éste será borrado por la tormenta posterior y el trabajo conjunto de quienes detentan cierto poder. A Martel no le importa tanto dejar claro la ocurrencia o no de determinados sucesos, sino qué acciones o reacciones son factibles de seguirlo; cómo determinadas complicidades pueden hacer desaparecer todo rastro y el no actuar implica también una posición moral.

Tras una primera lectura, más evidente, basada casi íntegramente en aquello que muestra explícitamente el relato, el film permite otra menos obvia que, por un lado, la refrenda y, por el otro, cuestiona la linealidad de cualquier interpretación. La ambigüedad con que la directora va llevando, en forma deliberada, la narración lleva al espectador a interrogarse por su propio papel en la situación aludida, poniéndolo en la disyuntiva entre obrar o no, revitalizando, de este modo, procesos de memoria acerca de los hechos concretos sucedidos en el pasado reciente.

Teniendo siempre en cuenta la cuestión moral, central en La mujer sin cabeza, este artículo se propone, en primer lugar, interrogarse acerca de la posibilidad de una lectura alegórica en la que el exceso en el significante, propio de cualquier alegoría, permita a Vero representar a la sociedad civil durante la dictadura y, en tal caso, a través de cuáles procedimientos estéticos esta alegoría es construida.

En segundo lugar, y como resultado de lo anterior, analizar el rol del espectador, prestando especial atención al punto de vista y la mirada que visibiliza, o no, al otro invisibilizado, ya sea por la pobreza o la desaparición física -en este caso, resultado del accidente, pero asimilable a la desaparición forzada en la dictadura por el silencio y la complicidad que la acompañan-. Tal análisis se abocará a poner de manifiesto los mecanismos por los cuales el relato constituye a quien visiona la película en testigo o posible partícipe de un proceso del borramiento, posición desde la cual se lo compelerá a una toma de una postura de índole moral. Por último, este artículo se propone demostrar cómo el film puede llegar a colaborar en la construcción de una memoria viva, es decir, una memoria encarnada en sujetos que la portan y mantienen abierto su sentido, generando continuamente nuevas interpretaciones (Feld, 2010). Una memoria de la dictadura que se vincula con un presente (el de la diégesis, pero también el de la aparición del film) en el que, lejos del aparato represivo, se reproducen algunos de sus efectos. 


\section{La alegoría nacional: la imposibilidad de representar el trauma}

Como "técnica que une dos planos de representación y de significación, uno aparente y otro velado" (Dufays 2014:23), la alegoría supone una articulación que se desarrolla dialécticamente entre dos instancias: una de producción o codificación, otra de interpretación o decodificación. Ambos polos se interrelacionan y demandan uno al otro. Si atendemos a la instancia productiva, la intención alegórica conlleva un ocultamiento de sentido que demanda la tarea, siempre incompleta, del receptor, que tiene que descifrar, revelar, aquello que se le escamotea. Si, en cambio, nos detenemos en el intérprete, vemos que la nueva lectura no sería posible sin un exceso deliberado en la instancia previa, de un plus en el significante que habilita el salto del sentido más evidente al figurado.

En cuanto a la alegoría en relación a la representación del trauma y la pérdida -que es específicamente el caso de La mujer sin cabeza y su alusión a los crímenes cometidos por la Dictadura- Dufays las clasifica, según el modo en que encaran el duelo, en dos tipos fundamentales, que remiten a su vez, a la categorización de Ismael Xavier³: alegorías transparentes y opacas, según lo faciliten o bloqueen. En el caso del film de Martel se trataría de una especie intermedia, que se coloca entre la obviedad y el hermetismo, dando cuenta de él pero dejando en sombras un resto indecible (2014:24; también en Tzvi Tal; 2005:139). $\mathrm{Si}$, además, nos detenemos en la vinculación que toda alegoría establece entre dominio meta y dominio fuente, según la conceptualización de George Lakoff, que retoma Lusnich para los films específicamente producidos durante la dictadura, podemos reconocer en $\mathrm{La}$ mujer sin cabeza una alegoría de tipo estructural que se extiende más allá del sistema de personajes hasta la situación argumental de base, fácilmente ligable con acontecimientos traumáticos de nuestra historia reciente.

Por último, un tipo particular de alegorías especialmente pertinente para este análisis, son las nacionales en las cuales la intención alegórica se vuelca a representar el destino de una nación en un momento determinado de su devenir. Dichas alegorías proponen una lectura transversal del contexto político y social aludido, y sus consecuencias en el presente del film, en general, a través de un salto del ámbito doméstico privado al ámbito público social e institucional.

Si bien, obviamente, este modo de entender la alegoría nacional se relaciona en sentido lato con los célebres planteos desarrollados por Fredric Jameson a propósito de la literatura, en sentido riguroso se aparta de éstos, puesto que para el pensador estadounidense todos los textos del Tercer Mundo -y solo ellos- son necesariamente alegóricos y, de un modo muy específico, alegorías nacionales. Y esto es así, precisamente, porque en dicho contexto no puede darse esta escisión entre lo doméstico y lo público; en él "la historia de un destino individual y privado es siempre una alegoría de la situación conflictiva de la cultura y la sociedad públicas" (2011: 171). No entraremos en una crítica detallada de esta lectura y sus supuestos ideológicos puesto que ya se ha hecho profusamente; solo puntualizaremos la utilización del concepto de alegoría nacional dentro de un marco teórico diverso ${ }^{4}$. 


\section{La mujer sin cabeza ¿una alegoría nacional?}

Como hemos dicho más arriba, el film comienza con un accidente, un descuido, una distracción que, dadas otras circunstancias, no hubiera pasado de una infracción de tránsito: atender el celular mientras se está conduciendo. La verdadera gravedad del acontecimiento aparece después, cuando la protagonista choca con algo y, aun así, no desciende del vehículo a ver qué se ha llevado por delante, ni brinda el socorro que, quizás, hubiera sido necesario, y, en cambio, huye. En el mismo momento en que, tras escapar, empieza a gestionarse su impunidad (hacia la mitad del film), comienza a establecerse un posible correlato con situaciones de envergadura nacional - la corrupción, los privilegios de determinada clase social, la facilidad para evadir la responsabilidad de un crimen- , aunque sin una datación concreta todavía. A medida que Vero va "recuperando su cabeza", es decir, va recobrando su identidad y su relación con su mundo cotidiano, y se cerciora tanto de la muerte del muchacho como de la desaparición de todo vestigio documental sobre el incidente, se habilita el anclaje de lectura alegórica, específicamente, en la dictadura. No sólo un chico ha desaparecido, sino que en principio no hay cadáver, el agua se ha llevado toda huella de lo que ha sucedido y, a nivel institucional, su muerte no consta como delito, ni tiene mayor importancia debido a su condición social ${ }^{5}$ : un adolescente que vive en los márgenes de la ciudad (allí donde se desarrolla la parte pobre y no llegan todos los servicios ni las principales $\operatorname{rutas}^{6}$ ) y, pese a su corta edad, trabaja informalmente ayudando a un jardinero.

Si bien no aparecen en el film los símbolos nacionales que Dufays considera más indicativos de dicha alegoría, tales como la bandera, el himno u otros más sutiles, como estatuas y retratos de héroes patrios (2014: 290), sí pueden encontrarse otros con la misma envergadura y significado, como son los organismos públicos que representan al Estado, tales como el Hospital, la Justicia (encarnada en el marido abogado y el primo juez) y, sobre todo, la Policía. Esta última, en especial, tiene un papel de relevancia a nivel institucional en dos escenas particularmente significativas: la primera, como instancia de registro y esclarecimiento de posibles delitos, cuando la familia de Vero quiere averiguar si les consta el hecho de una persona accidentada - si esa persona existe como tal, podríamos decir -, mediante una conversación que revela el grado de intimidad que tienen unos con otros; en segundo lugar, como instancia de represión, cuando fuerzan a una presa a salir del cubículo del baño en el que se había atrincherado en el Hospital al que la protagonista ha concurrido para recibir las primeras curaciones. Esta escena tiene un peso singular porque allí queda claro que Vero piensa que puede ser ella a quien se quieren llevar; surge por primera vez en el relato una situación que la iguala a otra mujer de distinta condición social, un contexto que las equipara: ninguna de las dos quiere ser aprehendida ${ }^{7}$.

Vero comienza a adquirir su peso metafórico en la medida en que todas estas instituciones se muestran como parte de una red de contención que la trasciende y protege, no requiriendo siquiera su participación activa. El relato da cuenta de ello no de una manera lineal, sino desde una ambigüedad que hace que en algunos momentos su figura pueda homologarse a la víctima traumatizada y en otros al victimario. Esta ambigüedad, construida sobre todo en 
base a recursos formales -sonido, encuadre, iluminación, focalización en su punto de vistafavorece la lectura alegórica. Se va creando un clima ominoso asemejable al de dictadura: los mismos sitios y personas pierden su rostro cotidiano, se vuelven amenazantes; pero, a su vez, el silencio y la acción de quienes detentan poder borran todo indicio de crimen, ocultan y protegen. De esta manera, Vero, en su dualidad y encrucijada moral puede leerse -nunca unívocamente- como la sociedad civil que sabe y no sabe qué está pasando, que sospecha que hay un crimen que está siendo ocultado -en este caso, el suyo, del que ni ella ni los espectadores están seguros- pero, aun así, es pasiva frente las decisiones de otros y termina, voluntaria o involuntariamente, formando parte de la red de silencio. Esta centralidad, que propicia el relato, no del crimen sino de la complicidad que se va tejiendo a su alrededor es uno de los elementos esenciales que habilita la lectura alegórica. Martel misma señala que esta película fue una indagación personal "acerca de algo que me resulta inexplicable en nuestra historia con respecto a la dictadura, que es la negación” (Enríquez, 2008).

Sin embargo, es necesario notar que -en sentido contrario a aquellas interpretaciones que llevan la suspensión de toda acción por parte de la protagonista hasta el final- en una de las últimas escenas, cuando el vehículo que protagonizó el accidente ya ha sido reparado (en otra provincia y sin estar ella advertida previamente) y, en apariencia, no queda ninguna huella en él del atropello, Vero marca con una seña muy sutil una parte del automóvil que todavía revela el hecho, pidiendo a su marido -sin decir palabra, pero sin dejar lugar a dudas- su total desaparición. Tal gesto muestra que ella no solo ha sido testigo pasivo del obrar de los hombres de la familia, sino finalmente parte activa de estas acciones. Tal ademán refrenda el círculo de impunidad, pero, estamos convencidos, no puede ser leído linealmente como comportamiento de la sociedad civil en su conjunto. Tampoco, creemos, está planteado así por el relato, a pesar de las contundentes declaraciones de Martel a Enríquez en este sentido.

Por otra parte, la constante referencia alegórica al pasado, que venimos señalando, no inhabilita una lectura más lineal, anclada en el presente de la diégesis, con la amplitud temporal puntualizada más arriba. En ella aparece como base de la anécdota central -una vez más, mediante determinados recursos formales- el tema de la pobreza y la marginación; la invisibilidad -literalmente, en el film- de aquellos que menos poseen y que han sido dejados fuera del sistema como consecuencia de políticas socio-económicas que, a pesar de los cambios de gobierno, se vienen perpetuando desde la Dictadura, más notoriamente en el contexto provincial. El accidente que, quizás, le costó la vida a un muchacho de raíces indígenas, perteneciente a la clase trabajadora, representa la colisión de dos mundos que, por otra parte, solo se relacionan tangencialmente. Unos sirven y otros son servidos, sin ser realmente vistos, salvo como esa mano que ayuda cuando se lo demanda. No hay una preocupación real en ninguno de los personajes centrales por quién es ese otro y cuáles son sus necesidades. Un trabajador puede ser reemplazado por otro imperceptiblemente, tal como sucede cuando el chico que ha muerto no puede concurrir a ayudar al jardinero $y$, tras confirmarse su deceso, es reemplazado por su hermano. El aspecto fantasmagórico que le otorga el relato, poniéndolos siempre fuera de foco o de cuadro, sumado a la presencia de fantasmas a las que reiteradamente se alude en el film -sobre todo, por boca de Lala- permiten tender un puente entre una y otra lectura: entre los desaparecidos en el 
proceso dictatorial y los excluidos por las políticas económicas que éste impuso y perduraron; ambos convertidos en nadie. ${ }^{8}$ Ahondan especialmente en el tema de los espectros Martin (2016) y Schwarzböck (2009).

\section{El conflicto moral}

Vero intenta atender el celular mientras maneja en una ruta casi desierta y, como consecuencia de esa distracción, atropella algo o a alguien. No lo sabe con certeza y, en realidad, elige no saberlo: el relato nos muestra tanto cómo ella sigue camino -después de dudar entre abrir o no la puerta del auto para ir a comprobar qué pasó-, como la imagen de un perro tirado en mitad de la carretera visto desde el espejo retrovisor. Su primera falta, entonces, es de omisión, quizás justificada por esa pérdida de "cabeza" que la aqueja debido al susto y el golpe (los dos sacudones de la colisión). Elige seguir camino y luego entra en una especie de aturdimiento que deja en suspenso cualquier determinación en cuanto a lo sucedido. Sólo hacia mitad del film aparece el conflicto moral claramente verbalizado, primero en el reconocimiento frente a su esposo "Maté a alguien en la ruta" (40:49) y luego con su hermano, cuando hace la pregunta clave “¿Qué tengo que hacer?" (44:20). La respuesta de éste condensa, de algún modo, el resto del relato: "Dormite", le aconseja él. Siguiendo este consejo, implícito en todas las acciones que le siguen a su confesión, Vero "dormirá" mientras la familia teje una red de impunidad alrededor de ella, una que preserve su sueño y haga innecesaria una segunda toma de decisión acerca de sumarse o no a los trámites que intentarán hacer desaparecer lo sucedido.

Una serie de afirmaciones tranquilizadoras vendrán a justificar su inacción: no hay registro policial de un accidente automovilístico, por lo que su primo concluye que no pasó nada; en el lugar del accidente solo se alcanza a ver un perro, por lo que su esposo afirma que, simplemente, se asustó; nadie parece echar en falta a nadie. Incluso cuando, varios días después, aparece un chico muerto en el canal cercano al lugar de la colisión, las autoridades afirman que se ahogó, y así se da a conocer la noticia en el periódico. La segunda toma de decisión parece ser, precisamente, creer en todo aquello que se le dice, en esa versión tranquilizadora de los sucesos. Por lo demás, el relato no es contundente acerca de aquello que en verdad ha acontecido: ¿atropelló Vero al chico que jugaba con su perro o éste simplemente se cayó al zanjón repitiendo alguna de las piruetas que hacía al principio del film? O, en todo caso, ¿por qué cree ella que sí lo hizo (y aun así no hace nada)? Y, finalmente, la pregunta clave: ¿cuál es la posición del espectador frente a esta cuestión?; o mejor, aún; ¿en qué posición instala Martel al espectador?

El modo en que el relato es construido es crucial para la toma de posición del espectador: la suma de ambigüedades lo coloca en una postura incómoda. Si bien el film está focalizado en Vero -solo poseemos la información que dispone ella- no nos podemos identificar, sin más, con la protagonista, aunque sí plantearnos sus dilemas. Los planos muy cercanos - primerísimos primeros planos y primeros planos, fundamentalmente, casi siempre de perfil o espaldas y en semioscuridad -, la falta de claridad con respecto a si en realidad atropelló al chico y la incertidumbre deliberada con la que avanza toda la narración, nos 
ponen en la misma situación que ella, pero, a la vez, abren un hiato de extrañamiento, crean una distancia que disloca la identificación: casi nunca vemos directamente aquello que ella ve; en cambio, la vemos a ella frente a cada situación. Nos transformamos en una suerte de testigos de su comportamiento y, como tales, somos llevados a preguntarnos qué hubiéramos hecho en su lugar. La cuestión ética aparece, así, en primer término, sobre todo desde momento en que se reconoce el delito: "maté a alguien y no me bajé."

Vero no quiere saber en realidad qué sucedió: no desciende enseguida del vehículo después del choque; ruega a su marido que no se detenga cuando, más tarde, rehacen el mismo camino en busca de certezas y ven un perro tirado a la vera de la ruta; no pregunta, específicamente, por los pormenores de la muerte del muchacho cuando se confirma su aparición en el canal que, desde de la tormenta, lleva mucha agua. Sin embargo, sutilmente, quiere saber de sí misma, de las consecuencias que tal episodio puede traer aparejadas para sí, apenas tiene la confirmación de que el muchacho murió: es entonces cuando va al Hospital en busca de las radiografías, se tiñe el pelo sin ayuda y, finalmente, confirma en el Hotel que no queda registro alguno de su paso, además de pedir que borren del auto los últimos vestigios del accidente. Es en ese momento, cuando el delito amenaza con salir a la luz, que se hace más patente la red de silencio y encubrimiento a su alrededor, y más clara su propia participación.

Los pocos rasgos de compasión por parte de Vero -o, simplemente, de una mirada más atenta hacia aquellos invisibilizados por su condición social- se dan después de que el deceso es corroborado, como el prepararle ella misma un sándwich al hermano del chico muerto, que pasa por su casa ofreciéndose a lavar su auto, o la intención de regalarle ropa (probablemente, de sus hijas). Antes, a pesar de haberse adentrado en el barrio pobre para acercar a la amiga de Candita que quiere dar el pésame a la familia, no tiene el menor gesto de condolencia ni intención de ayudar, aunque más no sea en forma indirecta.

Por el contrario, el relato muestra cómo, a su alrededor, se fortalece la red de encubrimiento que la protege a sus espaldas, hasta el momento culminante en el que ella misma toma la decisión más categórica, esa que la convierte en partícipe activa: pedir que desaparezcan los últimos vestigios del accidente, sepultar de modo definitivo su intervención en el suceso. ${ }^{9}$

La responsabilidad individual aparece diluida en el film, desde momento mismo de la confesión, en una responsabilidad más colectiva: la de toda su familia, que cuida muy bien que el secreto no se propague. El silencio será la más importante de las herramientas, una a la que todos ellos apelarán para cubrir los rastros. En este sentido, es muy importante, en la secuencia que muestra al inicio los chicos jugando, el primerísimo primer plano (ojos, nariz y boca) de uno de los niños de raíces indígenas, semioculto entre los arbustos, pidiendo silencio (1:35). Dicho gesto es la clave de todo el relato y, puesto que su mirada se dirige directamente a cámara apenas comenzada la película, un llamado de atención para el espectador. Analizada en retrospectiva, esta escena habilita la lectura en una doble dirección: el silencio con respecto al accidente y el silencio acerca de la exclusión de toda una clase social, esa a la que el muchacho representa. Esta mirada dirigida más allá de los límites de la diégesis involucra, asimismo, al espectador en la responsabilidad colectiva: el que calla es cómplice. 
La responsabilidad individual se transforma en una más colectiva, que se traspasa al sentido alegórico: la responsabilidad de toda una familia es la de toda una clase social o, si nos atenemos a la lectura de la propia Martel, de toda una sociedad ${ }^{10}$ que cobija con su silencio o su inacción la desaparición de personas, ya sea que estas sean desaparecidas por el Estado, es decir, secuestradas, torturadas y asesinadas por el Régimen dictatorial, ya sea que el sistema económico las excluya de tal modo que se invisibilicen, no cuenten realmente, no existan. ${ }^{11}$ Por otra parte, el hecho de que el muchacho haya terminado en un curso de agua -y que sea esta, justamente, la que borra las huellas que pueden ligar su muerte a un delito- refrenda la idea de una alegoría nacional en esta dirección.

\section{Memorias y (des)memorias de la dictadura}

¿Representa Vero, en su trauma o en su complicidad, una sociedad amnésica? ¿En qué medida puede decirse que el film colabora en la construcción de una memoria viva, es decir, impulsa la revitalización de procesos de interpretación y circulación de relatos referidos a hechos de nuestra historia nacional?

Más allá de declaraciones de la propia Lucrecia Martel en el sentido de que se propuso indagar acerca de una negación que, a su entender, involucró a la sociedad toda, el film propone muchos interrogantes y algunas respuestas. En primer lugar, el replanteamiento al espectador de cuestiones morales concomitantes a determinadas conductas (o a la ausencia de estas) reactualiza sus propias decisiones y responsabilidades en los períodos a los que el film se refiere -es decir, el de la dictadura y el del presente ampliado del film-, volviendo a poner en discusión un pasado que no debe ser ocluido, en el primer caso, o una clase marginada a la que no debiera dársele la espalda. ${ }^{12}$

Y esto es así, porque, a pesar de que el relato no es más que la detallada suma de las acciones llevadas a cabo para silenciar y ocultar acontecimientos y culpas, produce, paradójicamente, un efecto visibilizador de aquello que se quiere esconder, tal como sucede en la diégesis cuando el cuerpo que obstruía el canal sale a la luz, develando un terrible olor a podrido, al mismo tiempo que los vestigios del delito que se quiso ocultar. Todos los esfuerzos de la familia de Vero para borrar los rastros de lo sucedido no hacen más que poner -para el espectador- otra vez en foco no solo las huellas que delatan el hecho, sino el silencio mismo. Un silencio que aparece como el más claro y abarcador signo de complicidad.

En su afán por hacer desaparecer cualquier rastro del accidente, toda la familia obra solidariamente para no perder sus privilegios. Se puede decir que eligen cómo recordar lo sucedido, cómo (re)construir el pasado: sin vestigios del atropello. Y pueden hacerlo, precisamente, porque, como afirma Jelin, "cualquier intento de construir memoria se basa en una decisión acerca de qué recordar y qué olvidar" (2002:25). Al poner en escena el acto de elidir, el film no solo escenifica, mediante una alegoría, lo acontecido en el país durante la última dictadura -es decir, se convierte en lo que Feld llama un "escenario de memoria"13 -, sino que invita al espectador a revisar, desde una posición crítica, su propio papel en lo acontecido: la cuestión moral de la que hablábamos más arriba, pero también su rol en cuanto portador de una memoria colectiva que involucra a toda la sociedad. 
En tal sentido, es importante destacar cambios en el contexto histórico correspondiente al momento de la aparición del film -especialmente, las nuevas políticas de la memoria impulsadas por Néstor Kirchner a partir del 2003 y la reapertura de los juicios a los genocidas- que producen, a la vez, transformaciones en la capacidad de escucha de quienes son enfrentados con acontecimientos traumáticos del pasado reciente, en este caso el público en su rol de "testigo". Tales transformaciones abren la posibilidad a nuevas interpretaciones de períodos precedentes, impidiendo que la memoria se anquilose, no siendo ya realmente significativa para la comunidad.

Por otra parte, en tanto alegoría de la dictadura, el relato logra sortear el dilema del que habla Claudia Feld, a propósito de experiencias límites tales como la desaparición de personas, encontrando un lenguaje apropiado para su representación, a la par que pone en cuestión el carácter veritativo de la memoria, el rol del testimonio y las relaciones entre subjetividad y objetividad. Al evitar una categórica clausura en cuanto a la responsabilidad directa de Vero en la muerte del muchacho, Martel mantiene abierto el sentido global del film, revitalizando de ese modo las opciones por una memoria viva de lo sucedido.

\section{Conclusiones}

La mujer sin cabeza es un film deliberadamente ambiguo, por lo que cualquier interpretación categórica o lineal, ya sea del sentido más evidente o del figurado, invariablemente deja cuestiones de lado; en cierta medida lo falsea. Si el relato tiene huecos, incógnitas, situaciones que no se dejan atrapar con facilidad en una definición es porque, probablemente, la directora no ha querido posibilitar una lectura única; ni dos. O, en todo caso, su obra trasciende sus intenciones más voluntariosas de dar cuenta, sin más, de la negación o complicidad de la sociedad civil durante la dictadura, o, al menos, de hacerlo claramente. ¿Es Vero un ejemplo de toda una sociedad que, según la realizadora, prefirió no saber y paga por ello su costo traumático, tal como afirma en la citada entrevista de Enríquez? ¿O Vero es solo una paradigmática representante de aquello que Silvia Schwarzböck llama, refiriéndose precisamente a este film, la "clase acomodada", la clase privilegiada, tal como interpretan algunos teóricos como Schroeder Rodríguez o Rocío Gordon?

Por lo demás, es difícil, si se presta una ajustada atención al relato, considerar a Vero meramente un cómplice por su silencio, por hacer de cuenta que no pasó nada, tal como le repite su familia, o por su pasividad ante decisiones de otros, cuando ella misma pide que borren las huellas del accidente que permanecen en el auto tras su reparación, o se cerciora en la última escena de si consta su registro en el Hotel, último vestigio documental de su participación en el evento. Decididamente, tiene una participación activa, al menos sobre el final. Considerarla metáfora de la civilidad toda sería acentuar la responsabilidad global que ya le cabe, según Martel, a la sociedad por un silencio que considera signo de complicidad, o "por evitar darse cuenta de lo que está pasando" (Enríquez, 2008; el subrayado es mío), situación que puede considerarse intencional en el caso de Vero, que decide no bajarse del vehículo a comprobar qué pasó ${ }^{14}$, pero no tan clara en el caso de la sociedad civil como un todo sin distinciones. Remarcaría una acción deliberada de encubrimiento aplicable a toda ella en su conjunto. 
Por otra parte, al convertir al espectador en testigo del conflicto moral de la protagonista, el film propicia el replanteamiento de las cuestiones involucradas, reactivando procesos de rememoración capaces de revitalizar la memoria colectiva. De este modo, se evita una fijación que conspire contra una presencia más activa de ésta en los sujetos portadores que deben encarnarla y mantener su sentido abierto, generando continuamente nuevas interpretaciones (Feld).

La mujer sin cabeza puede, entonces, desde sus huecos, ambigüedades y sutiles planteos morales, a través de una lectura alegórica que la vincule con la última dictadura argentina, convertirse en un escenario de memoria capaz de traer de nuevo a la luz un pasado cuyas consecuencias obran aún en el presente. Puede, además, desde el presente ampliado de la diégesis, poner nuevamente en foco -a través del procedimiento estético inverso- una clase excluida por políticas económicas que la marginan e invisibilizan, invitando, además, a vincular ambas lecturas como causa y efecto. En tanto que el film exhorta al espectador a interrogarse acerca del rol que cada uno de nosotros está llamado a cumplir para evitar que el silencio y la corrupción se conviertan en el arma más eficaz de los perpetradores, la película puede ser leída como un alegato y una demanda, pero uno no con sentido lineal y mensaje simplista, sino uno que toma la forma de pregunta, a veces como un grito y otras como un susurro.

\section{Notas}

1. Así lo hacen, por ejemplo, Martin y Schroeder Rodríguez, conjuntamente con casi toda la bibliografía anglosajona.

2. La temporalidad del film ha sido ampliamente debatida, justamente, por esta falta de anclaje preciso. Estudios como el de los investigadores mencionados en el cuerpo del artículo anclan el film más puntualmente durante el menemismo, puesto que lo ligan, específicamente, a políticas neoliberales. Se basan, además, en ciertas declaraciones de la misma directora.

3. Xavier, I. (1999) "Historical Allegories" en A companion to film theory. Oxford: Blackwell Publishers.

4. El texto original de Jameson es de 1986, momento en el cual, deja claro Dufays, el concepto global de Tercer Mundo en el que se basa ya había caducado (2014: 15).

5. Cada miembro del entorno de Vero que se entera del suceso se interesa más por su suerte que por la de la posible víctima. Lo mismo sucede con las instituciones que representan al Estado. A pesar de la preocupación de la familia del chico por su desaparición, no hay constancia de que Policía lo esté buscando, lo cual supone o que no hicieron la denuncia, porque -por ejemplo- no confían en que puedan ocuparse realmente de ellos, o que quisieron hacerla y no se la tomaron, porque, efectivamente, no cuentan. Los bomberos solo encuentran el cuerpo buscando quitar lo que obstruye el canal. Esta falta de peso social que plantea el film es muy notoria cuando el chico, al comprobarse su muerte, es reemplazado por otro, sin más trámite, en la jardinería donde trabajaba.

6. Solo la intención de acortar camino lleva a Vero a la polvorienta ruta en cuyos márgenes juegan los chicos. Sólo un accidente hace que esos dos mundos tan distintos colisionen y, por lo tanto, se involucren más allá del trabajo, ocasional o no, que unos realizan para otros. 
7. La otra situación en la que Vero se equipara a alguien de otra condición social es la que tiene lugar en el baño de un club, tras recobrar el recuerdo del accidente. Allí, a su pedido, es abrazada y consolada por un plomero que está reparando una cañería. El hombre, también, la ayuda a refrescarse con una botella de agua que ha conseguido, ya que por los trabajos que está realizando no hay agua corriente. El grado de intimidad de esa escena es impensable entre Vero y un desconocido de la clase trabajadora en cualquier otra circunstancia.

8. Dice Martel: "La alienación entre clases sociales es tan grande que ellos, los otros, son fantasmas. Se trata, claro, de una visión infantil y enloquecida. Es tan ajeno a uno ese cuerpo, el color de esa gente, que en su locura la tía Lala los emparienta con los espantos. Yo eso no lo he inventado. No detecto bien de dónde los saqué, indudablemente de alguna de las mujeres viejas de la familia" (Enríquez, 2008).

9. Es curioso cómo esta escena, que de algún modo resignifica todo lo que ha venido sucediendo, es pasada por alto en casi todas las interpretaciones del film, incluyendo las académicas. Evidentemente, incomoda porque, en cierta forma, clausura la ambigüedad acerca de su responsabilidad: hay una acción positiva de encubrimiento y esto la coloca en una posición moral claramente censurable, haya o no dado muerte al muchacho. Es interesante cómo, con una ambigüedad inicial similar, el film iraní La decisión (Jalilvand, 2017), explora con toda hondura el comportamiento contrario en análoga situación.

10. Dice Martel: "Creo que esa es la marca histórica que tiene la Argentina, no comprender que el carácter de culpabilidad excede a la directa actuación sobre la muerte" (entrevista de Solomonoff, 2009: 82) "Cómo hicieron, los que no estuvieron implicados directamente en la militancia o en el aparato represivo, para negar lo que sucedía (...) Para mí el terror de la sociedad que no estuvo militando ni formó parte del aparato represivo es el terror de reconocer que sí sabían, que sí participaron de esa situación y que dejaron que pasara” (entrevista de Enríquez, 2008).

11. He aquí uno de los principales motivos de la equiparación, ya que "El desaparecido no tiene entidad, no está, ni muerto, ni vivo, está desaparecido". Jorge Rafael Videla, diario Clarín, 14/12/1979.

12. Dicen Páez Techio Marques y Beristain : "Es más probable que se recuerden los sucesos si se conmemoran, si son novedosos y tienen un gran impacto emocional". "Memoria social y Colectiva: Representaciones sociales de la historia" en J.F. Morales, M. Moya, E. Gaviria \& I. Cuadrado (Eds.) (2007). Psicología social. Madrid: McGraw Hill

13. El escenario de memoria es "un espacio en el que se hace ver u oír a un público determinado un relato verosímil sobre el pasado" (Feld, 2002:5)

14. En el momento del accidente y, por segunda vez, cuando recorre con su marido la ruta seguida el día del accidente hasta el lugar de los hechos, pero le pide que no se detenga a verificar si solo queda el rastro de un perro.

\section{Lista de Referencias Bibliográficas}

Casale, M. (2012). Lucrecia Martel: la realidad cuestionada. La presencia de lo siniestro como elemento desestabilizador. Ponencia presentada en el III Congreso Internacional 
de la Asociación de Estudios de Cine y Audiovisual. Publicación en Actas http://asaeca. org/download/lucrecia-martel-la-realidad-cuestionada-la-presencia-de-lo-siniestrocomo-elemento-desestabilizador/

Dufays, S. (2014) El niño en el cine argentino de la postdictadura (1983-2008). Alegoría y nostalgia. Woodbridge, UK: Tamesis.

Enríquez, M. (2008) La mala memoria en Radar/ Página12, 17/08/08.

Feld, C. (2010) "Imagen, memoria y desaparición. Una reflexión sobre los diversos soportes audiovisuales de la memoria" en Aletehia, Revista de la Maestría en Historia y Memoria de la FaHCE. Recuperado de: http://www.aletheia.fahce.unlp.edu.ar/numeros/numero-1/feld-claudia.-imagen-memoria-y-desaparicion.-una-reflexion-sobre-los-diversossoportes-audiovisuales-de-la-memoria/

Feld, C. (2002) Del estrado a la pantalla: las imágenes del juicio a los ex comandantes en Argentina. Madrid: Siglo XXI.

Gordon, R. (2015) “Suspensión: detenimiento y suspenso en la estética de Lucrecia Martel” en A contra corriente. Vol $13 \mathrm{~N}^{\circ} 1$, pag. 239-261.

Jelin, E. (2002) Los trabajos de la memoria. Madrid: Siglo XXI.

Jameson, F. (2011) "La literatura del Tercer Mundo en la era del capitalismo multinacional" en Revista de Humanidades $N^{\circ} 23$ (junio 2011), pag 163-193.

Lee, P. L. y Pradip N. T. (2012) "Public Media and the Right to Memory: Towards an Encounter with Justice" en Lee, P. L. y Pradip N. T. (ed) (2012) Public memory, public media, and the politics of Justice. England: Palgrave Macmillan, pag 1-22.

Lusnich, Ana Laura (2011) “Opacidad, metáfora, alegoría: nuevas estrategias discursivas y marcas de la ideología imperante en el cine ficcional del período 1976-1983" en Lusnich, A. L. y Piedras, P. Una historia del cine político y social en Argentina. Formas, estilos y registros, Volumen II. pág 467-485.

Martin, D. (2016). The cinema of Lucrecia Martel. Reino Unido: Manchester University Press.

Schroeder Rodriguez, P. A. (2016). Latin American Cinema: A Comparative History. Oakland, California: University of California Press.

Schroeder Rodriguez, P. A. (2014)." Little Red Riding Hood Meets Freud in Lucrecia Martel's Salta Trilogy" en Camera Obscura 87, Volume 29, Number 3. United States: Duke University Press.

Schwarzböck, S. (2009) “Los espantos" en Kilómetro 111, N 8, diciembre 2009, pag 166-171.

Solomonoff, J. (2009), "La realidad es lo que se decide que sea”, entrevista a Lucrecia Martel en La república del cine. Revista de la Academia de las Artes y Ciencias Cinematográficas de la Argentina, № 1, agosto.

Tal, T. (2005) Alegorías de memoria y olvido en películas de iniciación: Machuca y Kamchatka” en Aisthesis $N^{\circ} 38$ Pontificia Universidad Católica de Chile, 136-151

Abstract: The film, from 2008, proposes a story in which one can easily find correspondences with the disappearance of people during the Argentine military dictatorship: the disappearance of a body, a probable crime that is efficiently hidden, corruption and complicity. But, after the most obvious allegorical interpretation, there appears the possibility of 
another less obvious one that, on the one hand, endorses it and, on the other, questions it, through, above all, formal procedures. In this way, the story raises two readings that, however, are linked, relating, in addition, present and past: the disappeared of yesterday are the invisible of today, the result of a regime that spreads, beyond the limits of the dictatorship, through neoliberal economic policies that exclude them.

By putting these issues back in focus, the film morally challenges the viewer about its own role in both contexts.

Keywords: Dictatorship - silence - complicity - disappeared - neoliberalism - invisibility

Resumo: O filme, de 2008, propõe uma história na qual podem se encontrar correspondências com a desaparição de pessoas durante a ditadura militar argentina: a desaparição de um corpo, um provável crime que é eficientemente ocultado, a corrupção e a cumplicidade. Mas, após a leitura mais evidente -baseada quase que integramente no conteúdo explícito- aparece a possibilidade de outra menos obvia que, por um lado a referenda e, pelo outro, a questiona. Esta baseia-se na dualidade, também moral, que Martel vai construindo em forma deliberada e que leva ao espectador, por diversos mecanismos formais, a se questionar pelo seu próprio papel na sua situação aludida, seja como testemunha, ou seja como agente, fruto de uma identificação que o retrotrai à disjuntiva entre obrar ou não, revitalizando, deste modo, processos de memória no que diz respeito aos fatos concretos acontecidos no passado recente.

Entre a lembrança e a negação, La mujer sin cabeza aparece como o sintoma inocultável de uma sociedade na qual o silêncio converte-se em doença

Palavras chave: Ditadura - memória - silêncio - cumplicidade - desaparição.

[Las traducciones de los abstracts fueron supervisadas por el autor de cada artículo] 